\title{
Armies of Pestilence: CNS Infections as Potential Weapons of Mass Destruction
}

B.L. Hart and L. Ketai

X O-

\begin{abstract}
SUMMARY: Infectious agents have been investigated, developed, and used by both governments and terrorist groups as weapons of mass destruction. CNS infections, though traditionally considered less often than respiratory diseases in this scenario, may be very important. Viruses responsible for encephalitides can be highly infectious in aerosol form. CNS involvement in anthrax is ominous but should change treatment. Brucellosis, plague, Q fever, and other bacteria can uncommonly manifest with meningoencephalitis and other findings. Emerging diseases may also pose threats. We review infectious agents of particular concern for purposes of biowarfare with respect to CNS manifestations and imaging features.
\end{abstract}

God omnipotent is mustering in his clouds on our behalf armies of pestilence.

Richard II, Act 3, Scene 3

$\mathbf{S}^{\mathrm{h}}$ hakespeare had Richard II threaten his enemies with "armies of pestilence" from the clouds-a prospect that seems more plausible in our time when incidents involving anthrax, smallpox, and hemorrhagic fevers continue to make headlines. Many infectious agents have been developed during the past century for potential military use. By their nature, these are unconventional weapons more effective against unprotected, civilian targets than against soldiers; this attribute may make them attractive to terrorists. Among those organisms, some target the central nervous system. For others more commonly considered pulmonary or systemic agents, significant CNS effects may still result. Below, we review the historical background, some of the organisms considered at high risk for potential biowarfare or bioterrorism with a focus on neurologic implications, and potential future threats.

\section{Background: Public Health in Reverse}

Infections have accompanied warfare throughout history and have often caused more deaths than trauma. ${ }^{1}$ Occasional attempts

From the Department of Radiology, University of New Mexico, Albuquerque, New Mexico.

Paper previously presented in part at: Annual Meeting of the American Society of Neuroradiology and the Foundation of the ASNR Symposium, May 17-22, 2014;

Montreal, Quebec, Canada.

Please address correspondence to Blaine L. Hart, MD, Department of Radiology, MSC10 5530, 1 University of New Mexico, Albuquerque, NM 87131-0001; e-mail: bhart@unm.edu

- Indicates open access to non-subscribers at www.ajnr.org

http://dx.doi.org/10.3174/ajnr.A4177 were made to spread illness among enemies as a tool of warfare. One of the most notorious examples was giving blankets from smallpox victims to American Indians. Such effort, though reprehensible, in retrospect had limited impact in comparison with the widespread, natural impact of new diseases through the Americas. It is estimated that $95 \%$ of the American Indian population may have died as a result of exposure to smallpox, measles, and other European diseases. ${ }^{2}$ This demonstrates the potentially lethal effect of infectious diseases on an immunologically naïve population.

With the establishment of the scientific basis of germ theory, major improvement in public health followed. Clean water and sanitation had huge effects, and vaccines were developed. With scientific understanding, though, came the potential for what one general later termed "public health in reverse." With the exception of some effort to spread illness among animals, there was little attempt in this direction during World War I. However, revulsion at the results of gas warfare led to the Geneva Protocol after the war, which banned the use of not only gas but also germ warfare. Despite this ban, biologic warfare became a reality during World War II. The Japanese army did extensive research on several infectious agents, made numerous human tests on prisoners of war, and released weaponized plague against civilians in cities. Under air attack and fearing the potential use of anthrax, Great Britain began investigating anthrax as a potential weapon and enlisted the additional help of the United States. Aerosolized anthrax spread by an explosive device was tested on a flock of sheep on a small Scottish island. The lethal feasibility of this agent was established - and the island was considered contaminated and off-limits for $>40$ years; final decontamination in- 
volved removal of some soil and spraying the entire island with formaldehyde. ${ }^{3}$

The Cold War accelerated work by both the United States and the Union of Soviet Socialist Republics. The United States developed 5 infectious agents: anthrax, tularemia, brucellosis, Q fever, and Venezuelan equine encephalitis, in addition to toxins of biologic origin: botulinum and staphylococcal enterotoxin B. Information on the Union of Soviet Socialist Republics work is less available, but reportedly anthrax, plague, tularemia, glanders, brucellosis, smallpox, Venezuelan equine encephalitis, and Marburg virus were all weaponized. ${ }^{2,4}$ US research during the Korean War included tests on conscientious objectors in addition to animal experiments. Human exposures resulted in illness but no deaths. ${ }^{5}$ The United States announced a unilateral, complete end to all biologic weapons work in 1969, and all existing stocks were destroyed by 1973. Furthermore, it supported an international biologic weapons protocol, which has since been signed by 170 nations. A major limitation of this treaty, however, is the absence of any inspection or enforcement provision. A dramatic illustration of the dangers of such weapons came when anthrax was accidentally released from a Soviet military facility in Sverdlovsk in 1979. ${ }^{6-8}$ At least 66 deaths resulted, perhaps many more. Clandestine development of biologic weapons by other nations remains a concern because these weapons of mass destruction are both cheaper and less technologically challenging to produce than nuclear weapons.

Infections are also of concern as instruments of terrorism. Preparing and delivering such agents does require some technical expertise, but the potential is demonstrated by relatively recent history. The perpetrators of the sarin attack on the Japanese subway system in 1995 were found to have anthrax and Ebola cultures in their possession and had made earlier unsuccessful attempts at aerosolized anthrax attacks. ${ }^{9}$ Most notably, in October 2001, there was a domestic terrorist attack in the United States by anthrax sent through the mail. ${ }^{10,11}$ Twenty-two cases of anthrax resulted in 5 deaths.

\section{What Makes an Organism a Weapon?}

Certain characteristics make micro-organisms of special interest for these purposes:

They Can Be Grown. Not all organisms are easily grown. Viruses in particular vary considerably in ease of culture.

They Can Be Stored. For those nations that seek to develop these potential weapons of mass destruction, some "shelf life" is desirable. Hardy organisms or those that have a sporelike form have been especially sought.

They Can Be Delivered to a Population. Aerial delivery, the most likely delivery mechanism, and dispersion may involve significant force, and not all organisms could survive.

They Can Be Infective and Harmful. For most agents, infectivity involves entry via the respiratory system. "Weaponization" of these agents has involved preparing organisms or a medium to maximize the likelihood of causing infection. For example, anthrax spores in nature often clump together, resulting in a size too large to reach the alveoli. Laboratory-prepared, weaponized an- thrax is designed to deliver individual spores that are small enough to reach the alveoli.

Harmful agents may not be lethal. Lethal infections may have obvious advantages for military or terrorist purposes, but some infections, "incapacitating agents," may be effective at tying up military resources or spreading panic among civilian populations.

A limited list of infectious agents meets all or some of these criteria for use as a weapon. Some of these agents have occasional CNS effects, while others more specifically target the CNS.

\section{Anthrax}

Anthrax is the arch villain of biowarfare, hardy and lethal. Bacillus anthracis is an encapsulated, Gram-positive bacterium, found naturally in soil, most commonly affecting herbivorous animals (cattle, sheep, and goats). ${ }^{12,13}$ Anthrax endospores are resilient and can survive for decades in the soil. Endospores that enter the body are phagocytized by macrophages. Germination causes activation to vegetative bacteria, with subsequent potential septicemia. The 3 peptides secreted by $B$ anthracis combine to form exotoxins: edema toxin and lethal toxin. ${ }^{12}$ Human exposure can occur through the skin, ingestion, or inhalation. A fourth route of infection has been described more recently in heroin users. ${ }^{14-16}$

Most anthrax cases in the world, up to $95 \%$, are cutaneous forms. ${ }^{13}$ The characteristic lesion is a painless, pruritic papule that develops a vesicle. Central necrosis results in a classic black eschar that gives the name to the disease, from the Greek for coal or charcoal. Although the lesions may be self-limiting, antibiotic treatment is recommended. Severe edema can infrequently result.

Ingestion of contaminated meat results in gastrointestinal anthrax. Manifestations include ulcerations, edema, fever, abdominal pain, constipation or diarrhea, and ascites. An uncommon form is oropharyngeal anthrax. Although oropharyngeal is usually less serious than gastrointestinal anthrax, cervical edema and lymphadenopathy can cause respiratory distress and dysphagia.

Inhalational anthrax is uncommon in nature but often fatal. It is also one of the most investigated and feared forms of potential biowarfare. The 1- to $2-\mu \mathrm{m}$ size of the spores lends itself to inhalation and deposition in the alveoli. Rather than causing a primary pneumonia, inhaled spores are transported by macrophages to mediastinal lymph nodes, where they germinate and release toxins. Hemorrhagic mediastinitis and septicemia follow. The clinical illness is classically biphasic, an initial nonspecific phase of fever, nonproductive cough, and myalgia followed several days later by fulminant illness and death. Sometimes, but not always, there is a brief intervening respite before the fulminant phase. ${ }^{17}$ Mediastinal widening is present on chest radiographs or CT, and effusions are often seen. CT can show high attenuation within hemorrhagic nodes. ${ }^{10,18}$

A new type of infection, injectional, was described as a result of an unusual outbreak of anthrax in Scotland, England, and Germany in 2009 and 2010 among heroin users. ${ }^{14,15,19}$ Soft-tissue infections were characterized by disproportionate edema, less pain than that seen in necrotizing fasciitis, and relative lack of prominence of fever. Among 119 cases (47 considered confirmed and 72 probable or possible), 14 deaths occurred. A smaller, similar outbreak occurred in 2012-2013 in heroin users in Europe. ${ }^{16}$ 

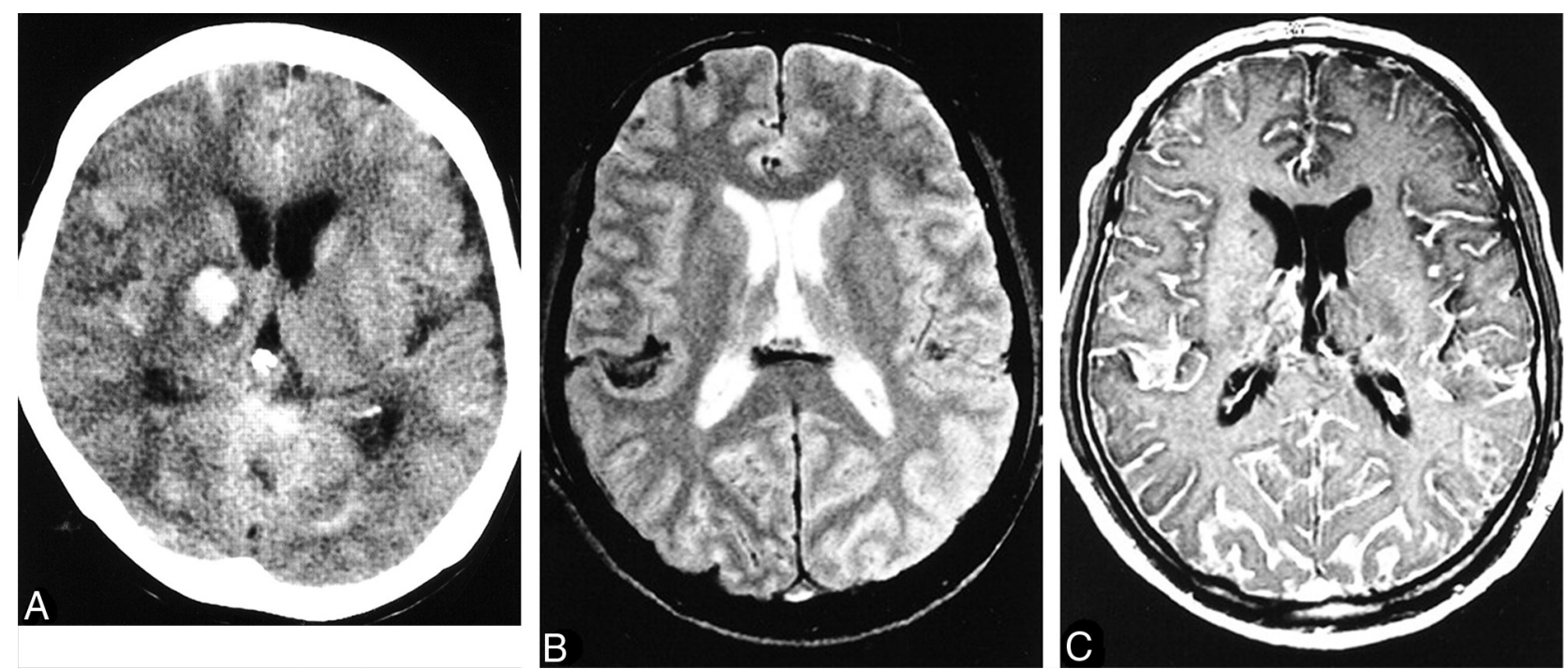

FIG 1. Anthrax meningoencephalitis. Noncontrast CT $(A)$ of a patient with gastrointestinal anthrax shows subarachnoid, intraventricular, and parenchymal hemorrhage. MR imaging of a different patient shows subarachnoid hemorrhage on axial T2 gradient-recalled ( $B$ ) imaging and diffuse leptomeningeal enhancement after gadolinium administration (C). Reprinted with permission from Kim et al. ${ }^{21}$

It is suspected that heroin may have been contaminated during transportation to Western Europe.

Meningitis may occur as a complication of any of these forms, most likely from hematogenous spread. ${ }^{12,20}$ Anthrax meningitis is usually fatal. CSF may contain large amounts of blood and organisms, and pathologic postmortem examination shows hemorrhagic meningitis, severe edema, and inflammatory infiltrates. $^{7,12}$ The few reports of imaging describe subarachnoid hemorrhage and leptomeningeal enhancement on CT and MR imaging and sometimes intraventricular and parenchymal hemorrhage (Fig 1)..$^{21,22}$ Leptomeningeal enhancement helps distinguish meningitis from other causes of subarachnoid hemorrhage. Although anthrax meningitis has been described as rare in naturally acquired cases, examination of the 3 large outbreaks mentioned above reveals a different picture. Years after the Sverdlovsk outbreak, results of postmortem examinations were published. Half of the 42 reported cases had hemorrhagic meningitis. ${ }^{7}$ One of the 5 patients who died in the US mail bioterrorism attack had hemorrhagic meningitis. ${ }^{10,11}$ Of the 13 deaths in confirmed anthrax cases in the Scottish outbreak, 4 resulted from hemorrhagic meningitis. ${ }^{19,23}$ This $20 \%-50 \%$ rate of meningitis in fatal cases shows the ominous prognosis of anthrax meningitis and a higher rate in these outbreaks than reported in the past in sporadic cases. Guidelines for the management of anthrax from a Centers for Disease Control and Prevention expert panel published in February 2014 make the presence or suspected presence of meningitis a key decision point in treatment. ${ }^{24}$ If meningitis is suspected, 3 drugs are recommended, including high-CNS-penetration drugs, and antitoxin therapy and steroids may be of benefit (though data are limited). Detection of hemorrhagic meningitis should thus trigger specific and aggressive treatment.

\section{Nightmares from the Past}

Two of the major pestilences from the past are of concern as potential weapons of mass destruction. Smallpox, caused by the DNA virus Variola, was a cause of enormous devastation. Highly infectious, it caused approximately $30 \%$ mortality in unvaccinated subjects. The fact that humans are the only host made possible its elimination from nature by an unprecedented public health vaccination program. ${ }^{25}$ The only known remaining samples are held under tight security in strict laboratory conditions in the United States and Russia (though a forgotten sample was recently found in a laboratory freezer and quickly moved). That very success, however, means that much of the world now has little or no immunity against smallpox. The potential for terrorist or rogue state use of smallpox has led to contentious and continuing debate about the fate of the remaining laboratory stores, the course of research, and the appropriate timetable for destruction of those samples. Clinical manifestations of smallpox are primarily cutaneous and pulmonary, not neurologic.

Plague, on the other hand, still exists in nature and causes disease. ${ }^{26}$ Yersinia pestis, a nonmotile, Gram-negative bacillus, was the cause of several great pandemics, including the Black Death that killed a third of the population of Europe in the 14th century. ${ }^{27}$ Bubonic plague occurs when infected fleas, part of an enzootic cycle with a rodent population, bite a human and cause regional lymphadenitis. Secondary pneumonia or septicemia may occur, with serious or fatal consequences. Primary septicemic plague, without bubo formation, has a high mortality. Pneumonic plague is uncommon in nature but is the form to be expected in a deliberate aerosol attack. Early treatment would be critical for survival. Some 5-15 cases of plague per year, mostly bubonic, occur in the United States, most in the Southwest. A review of $>100$ cases in the United States found that $6 \%$ had plague meningitis. ${ }^{28}$ Most of these were patients with bubonic plague, presumably with hematogenous spread to the meninges. Primary plague meningitis probably does not occur. There have been suggestions that meningitis is more likely to occur with axillary or cervical buboes, though statistical evidence is not strong. ${ }^{28}$ There is better evidence that patients with inadequate early treatment are at higher risk of developing meningitis. ${ }^{28-30}$ 


\section{Other Bacterial Agents}

Tularemia was weaponized by the United States and the Union of Soviet Socialist Republics ${ }^{2}$ and is among the agents to which volunteers were exposed during development in the Cold War. ${ }^{5}$ Francisella tularensis, a small Gram-negative intracellular coccobacillus, is the cause of tularemia and is found naturally in animals, including infected rabbits (whence the term "rabbit fever"). Humans can become infected by direct contact with animals, through ingestion, through contaminated ticks, or by inhalation. Human-to-human transmission is not reported. Naturally acquired cases are most commonly ulceroglandular, resulting in fever, chills, and a cutaneous ulcer with lymphadenopathy. Less common forms include typhoidal, oropharyngeal, and pneumonic. Tularemia can cause significant morbidity and mortality. Aerosolized delivery is the greatest concern for biowarfare use. The disease is highly infectious from as few as 10 inhaled bacteria. Pulmonary tularemia has occurred in a number of landscape workers in Martha's Vineyard and elsewhere. Typical features are bilateral bronchopneumonia, sometimes with cavitation, and lymphadenopathy and pleural effusions in about one-third of patients. ${ }^{18}$ Meningitis or cerebral abscesses are rare complications of tularemia. ${ }^{31-33}$ There are no specific imaging features reported for tularemic meningitis, but notable laboratory aspects are mononuclear predominance in the CSF and sometimes delay in diagnosis because of difficulty of culture. ${ }^{31}$

$\mathrm{Q}$ fever is caused by Coxiella burnetii, an obligate intracellular, rickettsia-like organism found worldwide, which is highly infectious and produces a resistant, sporelike form. ${ }^{34}$ Unlike anthrax, however, Q fever causes few deaths but prolonged, incapacitating illness. Acute Q fever can cause nonspecific febrile illness, pneumonia, hepatitis, or meningoencephalitis. Meningitis can occur without pneumonia. ${ }^{35}$ Chronic forms are uncommon but serious and include endocarditis, chronic hepatitis, and osteomyelitis. A review of 121 cases of acute Q fever found $>40 \%$ with neurologic symptoms, most commonly headache and confusion. ${ }^{36}$ Clinical meningitis is less common. ${ }^{36,37}$ The laboratory picture of $C$ burnetii meningitis is similar to that of aseptic meningitis, generally a mild lymphocytic pleocytosis, with the important distinction that it is treatable with antibiotics. CT and MR imaging findings are usually normal, but there are reported cases of encephalitis findings on imaging. ${ }^{37}$

Brucellosis is caused by facultative intracellular bacteria of the Brucella genus, most commonly Brucella melitensis, which infects sheep, goats, cattle, swine, and dogs. Humans are infected by contact with infected animals or food, especially unpasteurized dairy products, but the disease is readily spread by aerosol, with a number of laboratory infections known. ${ }^{38,39}$ Brucella species were previously adapted for military biowarfare and are considered a possible bioterrorism agent. The reticuloendothelial system is the usual target, but granulomatous disease can occur in many organs. Clinical manifestations include acute febrile illness; chronic, undulant fevers; bone or joint disease in approximately one-third of patients, which can include spondylitis; genitourinary infections; hepatitis; lung infection; endocarditis, which, though rare, is responsible for most deaths; and neurologic disease in approximately $5 \%-10 \%$ of cases. Both peripheral and central nervous systems can be affected, and sensorineural hearing loss is com-
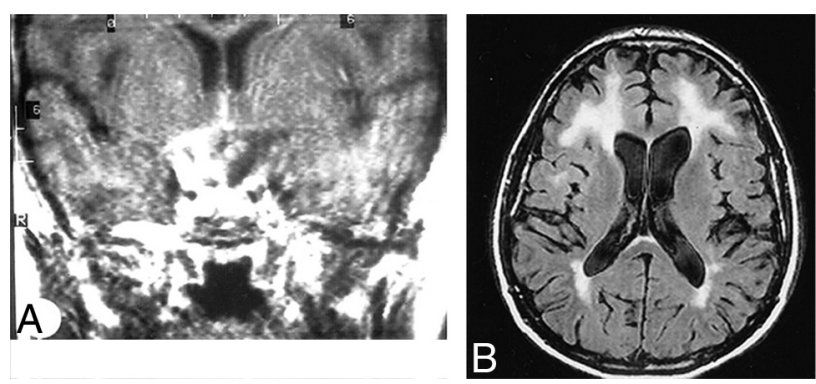

FIG 2. Neurobrucellosis. Coronal postgadolinium MR imaging $(A)$ shows sellar and suprasellar thickening and enhancement, presumed granuloma formation. Abnormalities resolved after treatment. Axial FLAIR ( $B$ ) of a different patient shows extensive white matter hyperintensities in a 50-year-old patient. White matter changes in brucellosis may be due to demyelination, perhaps from autoimmune reaction. Meningeal enhancement and vascular changes are also reported in brucellosis. Reprinted with permission from Al-Sous et al. ${ }^{41}$

mon. Effective treatment of CNS disease requires months of triple drug therapy. CNS disease can be the first or predominant presentation. ${ }^{40}$ Imaging findings can be normal in many cases $^{40,41}$; a review found 10 of $23 \mathrm{MR}$ imaging studies with normal findings. Observed abnormal findings include the following: inflammation with dural, leptomeningeal, or lumbar nerve root enhancement, and suprasellar granuloma formation; white matter changes, focal or diffuse, likely due to demyelination; and vascular findings, lacunes, or small hemorrhages (Fig 2). ${ }^{41}$ Endocarditis may also lead to embolic disease or mycotic aneurysms.

\section{Viruses: Encephalitis and Hemorrhagic Fevers}

A number of viruses most known for causing encephalitis are considered potential tools for deliberate attack. ${ }^{42}$ Most viral encephalitides are arboviruses transmitted in nature by mosquitoes but are also transmissible by aerosolization, which would most likely be implemented by a bioweapon. Hemorrhagic fever viruses also are potential bioweapon agents. Many of these illnesses result in nonspecific imaging findings, and for others, there is limited information available on imaging findings. We review here some candidate viruses with notable imaging or clinical features; the list is not exhaustive.

The most common cause of viral encephalitis is Japanese encephalitis, a flavivirus common in eastern and southern Asia and the Pacific Rim transmitted by mosquitoes. ${ }^{43,44}$ Other neurotropic flaviviruses cause St Louis encephalitis, West Nile virus, and Murray Valley encephalitis. As with other viruses in this family, many subclinical infections occur. In addition to nonspecific febrile illness, aseptic meningitis, encephalitis, and acute flaccid paralysis from anterior horn cell involvement may occur. Movement disorders are common. There is a strong predilection for involvement of the thalamus (Fig 3). A review of 42 patients with Japanese encephalitis found abnormal CT findings in 55\% of patients and abnormal MR imaging findings in all patients. The thalami were abnormal in $94 \%$ of MR images. ${ }^{45}$

West Nile virus has gained considerable attention since arriving in the United States several years ago. Many West Nile infections are asymptomatic or only mildly symptomatic, and 


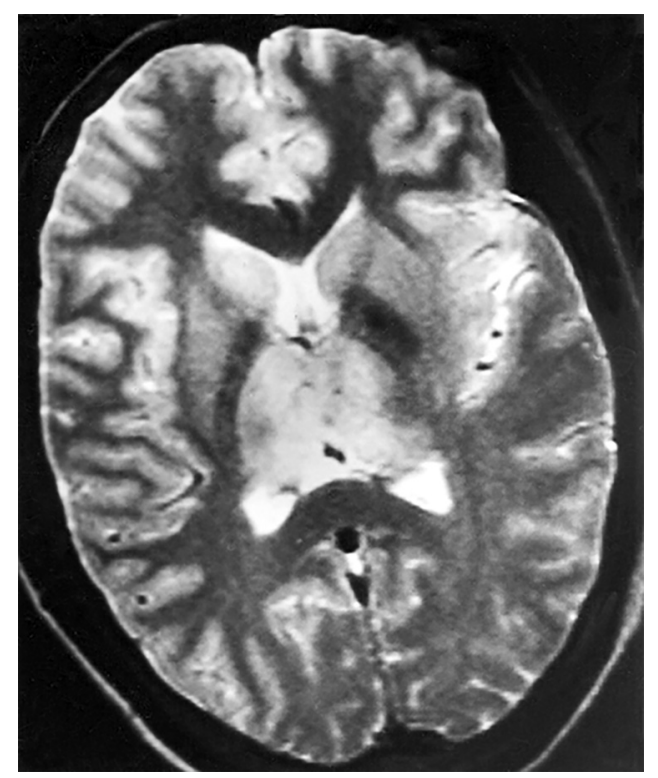

FIG 3. Japanese encephalitis. Axial T2-weighted MR imaging shows bilateral hyperintensity in the thalami and basal ganglia. Reprinted with permission from Kalita et al ${ }^{44}$ Copyright $\odot$ 2003, American Medical Association. All rights reserved.

a minority of patients develop fever, myalgias, headache, lymphadenopathy, and rash. Clinical encephalitis is serious, with a worse outcome in the elderly. Imaging features of West Nile encephalitis are nonspecific and range from normal to diffusiononly abnormalities to scattered $\mathrm{T} 2$ hyperintensities and, less commonly, parenchymal or meningeal enhancement. Normal and diffusion-only patterns appear to correlate with better clinical outcome, while more extensive abnormalities are associated with worse clinical outcome. ${ }^{46}$ In addition to encephalitis, West Nile infection can result in myelitis, causing a poliolike illness. ${ }^{47,48}$ Imaging abnormalities in the spine can include spinal cord or nerve T2 hyperintensity or enhancement. ${ }^{46}$

Equine encephalitis viruses, of which there are 3 major types in the Western hemisphere, have been of special interest for biowarfare. These alphaviruses are fairly readily grown, highly infectious by aerosol ( $>100$ accidental laboratory infections have occurred), and relatively stable. ${ }^{49}$ Venezuelan equine encephalitis was weaponized or investigated by several nations, including the United States and the Union of Soviet Socialist Republics. Venezuelan equine encephalitis results in a high rate of illness but a fairly low rate of encephalitis. There is relatively little information on imaging findings, to our knowledge. Most cases of Western encephalitis virus infection cause only mild symptoms. The development of frank encephalitis, however, as in any of the equine encephalitides, often causes major morbidity. Eastern encephalitis has a lower symptomatic infection rate but more frequently causes clinical encephalitis, with an especially high case fatality rate (50\%$75 \%) .{ }^{50}$ Eastern encephalitis also has more specific imaging features than most viral encephalitides. Most reports note early basal ganglia and thalamic involvement, which is a distinguishing feature from herpes simplex encephalitis (Fig 4). ${ }^{50-52}$ In all of these equine viral encephalitides, the elderly and very young are affected most severely.

Hemorrhagic fever viruses are RNA viruses that attack the vas-

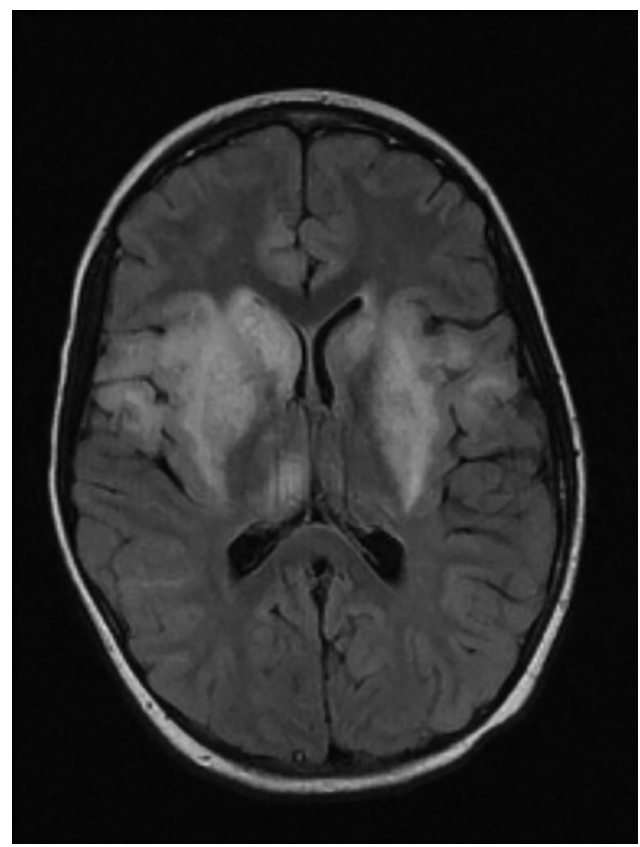

FIG 4. Eastern equine encephalitis. FLAIR image illustrates basal ganglia involvement typical in this disease and involvement of the thalami, insula, and more peripheral cortex. Reprinted with kind permission from Springer Science and Business Media from Lury and Castillo. ${ }^{51}$

culature. Increased blood permeability leads to hypovolemia and shock, with variations in specific organ involvement among the different viruses. For example, Rift Valley and yellow fever virus frequently cause hepatitis. Encephalitis has been reported as a rare complication of Rift Valley fever. ${ }^{18,53}$ Hemorrhagic complications are more common with the Filoviradae family. These include the Ebola virus, center of much attention and fear, and the Marburg virus, which was weaponized by the Union of Soviet Socialist Republics and also causes severe illness. Mortality rates from both viruses are in the range of $60 \%-90 \%$. Information on imaging findings is sparse.

Although often mild or asymptomatic, dengue virus can cause hemorrhagic fever. There have been controversial allegations regarding the use of dengue as a biowarfare agent. Dengue is a widespread problem, with an estimated 100 million cases of symptomatic infection annually. Also a flavivirus, it is endemic in tropical and subtropical countries. Infection can be asymptomatic but can also result in dengue fever, with fever, headache, abdominal pain, and muscle, bone and joint pain; dengue hemorrhagic fever, with thrombocytopenia, increased vascular permeability, and hemorrhagic complications; and dengue shock syndrome. ${ }^{54}$ Because of the sometimes severe hemorrhagic or metabolic complications, there is a variety of possible causes of dengue encephalopathy other than direct CNS infection. These include liver or renal damage, dehydration, and electrolyte imbalances. In addition, dengue viral encephalitis can occur, and separating secondary encephalopathy (in dengue hemorrhagic fever) from dengue viral encephalitis may be difficult. ${ }^{55}$ Imaging findings are nonspecific but include $\mathrm{T} 2$ hyperintensities in a variety of locations. ${ }^{55,56}$ Intracranial hemorrhage can be seen, and encephalopathy or shock may be accompanied by imaging findings of ischemic injury (Fig 5). 

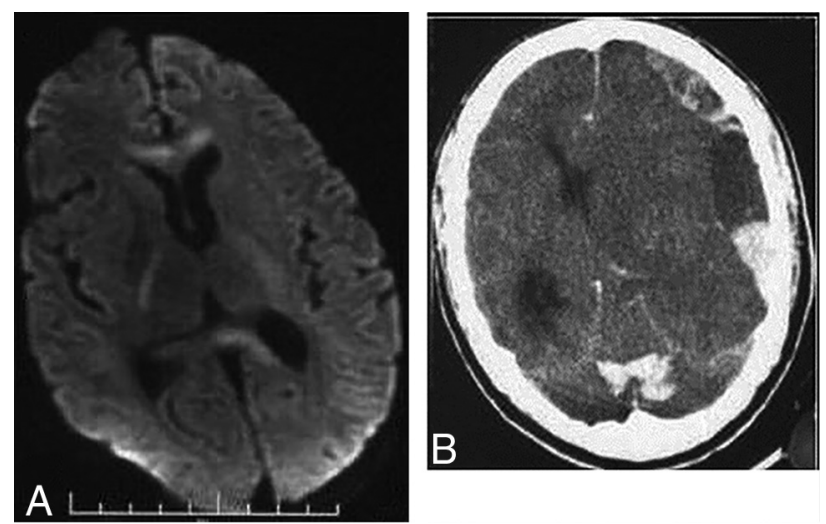

FIG 5. Dengue. DWI $(A)$ shows increased signal in the genu and splenium of the corpus callosum and posterior limbs of the internal capsules in a patient with dengue encephalopathy. Areas of edema or restricted diffusion in dengue encephalopathy are nonspecific and variable. Noncontrast CT of a different patient $(B)$, with dengue shock syndrome, shows subdural and parenchymal hemorrhage. Intracranial hemorrhage is uncommon in dengue, even in those with systemic and cutaneous hemorrhagic complications. Reprinted from Bhoi et al ${ }^{55}$ with permission from Elsevier.

\section{New or Emerging Diseases}

New infectious disease threats are a constant possibility for a variety of reasons. New viruses are still being discovered, usually following an outbreak. Serious, frightening illnesses such as those due to coronaviruses bring extensive public concern. Pulmonary hantavirus came to attention in 1993 when multiple patients in the US Southwest presented with noncardiogenic pulmonary edema and respiratory failure, with high mortality. The responsible hantavirus was previously unrecognized. Other hantaviruses in Asia and Europe typically affect the kidneys.

Mutations change the infectious nature of organisms. Influenza virus, for example, is particularly notorious for constant change. Influenza, though most commonly causing pulmonary disease, can sometimes have serious neurologic consequences.

Diseases can also change or become serious when environments change. An example of an emerging disease with major CNS consequences is Nipah encephalitis. The responsible agent is a paramyxovirus for which fruit bats constitute the natural reservoir. An outbreak in Malaysia in 1999 caused >200 cases of human infection, with nearly $40 \%$ mortality. ${ }^{57}$ The generally accepted reason for the sudden outbreak of human infection relates to the expansion of pig farming in or near orchards or the jungle. The likely pathway ensued when bats dropped partially eaten fruit contaminated with the virus, pigs would eat the fruit and become infected, and humans, in turn, became infected from pigs. Subsequent investigation has shown human infections from other intermediate animals, occurring without intermediate animal hosts, and also human-to-human transmission. ${ }^{58}$ Pathologic findings include endothelial infection of small blood vessels in the CNS, with thrombotic occlusion and microinfarction. Imaging findings in acute Nipah encephalitis include multiple small, discrete lesions on MR imaging, likely the result of vasculitis (Fig 6). Spinal cord lesions may occur. ${ }^{59}$ Chronic or recurrent forms can also occur, with a more confluent appearance of $\mathrm{T} 2$ hyperintensity in the cortex. ${ }^{59,60}$

Chikungunya, caused by an alphavirus, is re-emerging after

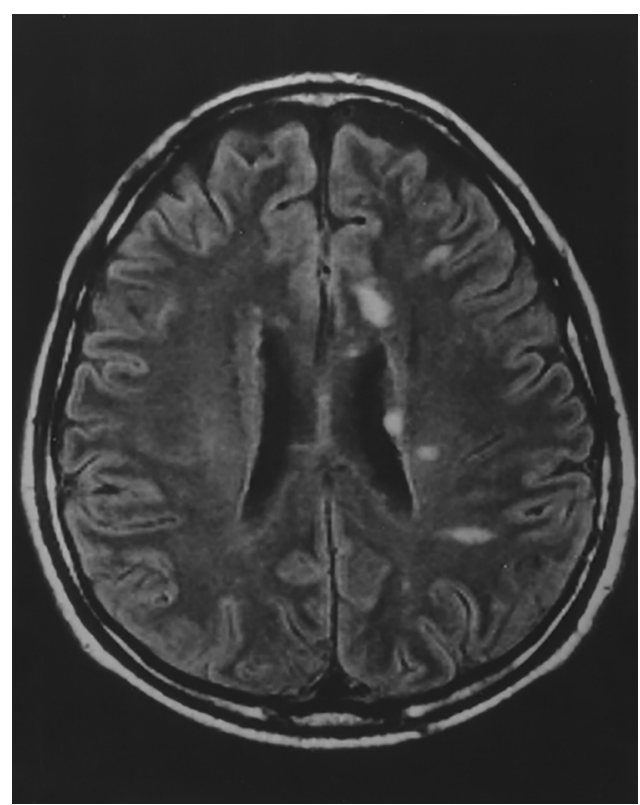

FIG 6. Nipah encephalitis, acute findings. Multiple discrete lesions on FLAIR are consistent with vasculitis reported on pathologic studies. Reprinted from Sarji et $\mathrm{al}^{60}$ with permission from the American Journal of Roentgenology.

decades of quiescence. Natural spread is by mosquitos, especially the same Aedes species that carry dengue. Epidemics exploded around the Indian Ocean in 2005. A different strain appears to be responsible for the recent outbreak in the Western hemisphere in $2013{ }^{61}$ Local transmission in the United States began in the summer of 2014. Chikungunya infection is characterized by fever, rash, headache, and, most notably, polyarthralgias, which can be debilitating and chronic. ${ }^{62}$ Encephalopathy, meningoencephalitis, flaccid paralysis, and Guillain-Barré syndrome are uncommon manifestations. ${ }^{63}$ Vertical (mother-to-child) transmission can cause encephalopathy in the child, with areas of restricted diffusion on MR imaging during the acute phase. ${ }^{64}$

The likelihood of emerging infections used for purposes of biowarfare is unknown, but some of these viruses can be highly infectious and harmful. Such traits may be enticing for nefarious purposes. ${ }^{65}$ Moreover, there is greater potential than ever before for deliberate genetic manipulation of infectious agents. Such manipulation could result in greater virulence or resistance to antibiotics or vaccines. There are reports that Soviet biowarfare research included attempts to create chimera viruses combining smallpox with virulence genes from the Ebola virus, for example. $^{25}$

\section{CONCLUSIONS}

Armies of pestilence have been used for both military and terrorist purposes in the past and remain a threat. Several potential biowarfare infections cause abnormalities relevant to neuroimaging. Hemorrhagic meningitis should suggest anthrax. Although carrying a grim prognosis, hemorrhagic meningitis in anthrax should change treatment. Meningitis can also occur in several unusual diseases, including plague, Q fever, and tularemia, and is treatable with appropriate antibiotics. CNS findings in brucellosis are protean and can include inflammatory changes, demyelination, and 
vascular disease. Among the many different forms of viral encephalitis, Eastern equine and Japanese are notable for deep gray matter predilection. New or changed diseases remain a constant threat. In the appalling event of deliberate use, prompt recognition would be especially important.

Disclosures: Blaine L. Hart—UNRELATED: Grants: National Institutes of Health grant: U54 NS065705. Loren Ketai-UNRELATED: Grants: National Institutes of Health grant: R01AT007171.

\section{REFERENCES}

1. Martin JW, Christopher GW, Eitzen EM. History of biological weapons: from poisoned darts to intentional epidemics. In: Dembek ZF, ed. Medical Aspects of Biological Warfare. Washington, DC: Borden Institute; 2007:1-20

2. Croddy E. Chemical and Biological Warfare: A Comprehensive Survey for the Concerned Citizen. New York: Copernicus Books; 2002

3. Manchee RJ, Broster MG, Stagg AJ, et al. Formaldehyde solution effectively inactivates spores of Bacillus anthracis on the Scottish island of Gruinard. Appl Environ Microbiol 1994;60:4167-71

4. Cook MS, Woolf AF. Preventing proliferation of biological weapons: US assistance to the former Soviet states. Published April 10, 2002. http://oai.dtic.mil/oai/oai?verb= getRecord\&metadata Prefix $=$ html\&identifier $=$ ADA454722. Accessed August 1, 2014

5. PBS: American Experience. The Living Weapon. http://www.pbs.org/ wgbh/americanexperience/features/transcript/weapon-transcript/. Accessed August 1, 2014

6. Meselson M, Guillemin J, Hugh-Jones M, et al. The Sverdlovsk anthrax outbreak of 1979. Science 1994;266:1202-08

7. Abramova FA, Grinberg LM, Yampolskaya OV, et al. Pathology of inhalational anthrax in $\mathbf{4 2}$ cases from the Sverdlovsk outbreak of 1979. Proc Natl Acad Sci U S A 1993;90:2291-94

8. Ragg V. Russia: anthrax in the Urals. Lancet 1992;339:419-20

9. Takahashi H, Keim P, Kaufmann AF, et al. Bacillus anthracis bioterrorism incident, Kameido, Tokyo, 1993. Emerg Infect Dis 2004; 10:117-20

10. Jernigan JA, Stephens DS, Ashford DA, et al. Bioterrorism-related inhalational anthrax: the first $\mathbf{1 0}$ cases reported in the United States. Emerg Infect Dis 2001;7:933-44

11. Jernigan DB, Raghunathan PL, Bell BP, et al. Investigation of bioterrorism-related anthrax, United States, 2001: epidemiologic findings. Emerg Infect Dis 2002;8:1019-28

12. Dixon TC, Meselson M, Guillemin J, et al. Anthrax. N Engl J Med 1999;341:815-26

13. Purcell BK, Worsham PL, Friedlander AM. Anthrax. In: Dembek ZF, ed. Medical Aspects of Biological Warfare. Washington, DC: Borden Institute; 2007:69-90

14. Ramsay CN, Stirling A, Smith J, et al. An outbreak of infection with Bacillus anthracis in injecting drug users in Scotland. Euro Surveill 2010;15:pii:19465

15. Palmateer NE, Ramsay CN, Browning L, et al. Anthrax infection among heroin users in Scotland during 2009-2010: a case-control study by linkage to a national drug treatment database. Clin Infect Dis 2012;55:706-10

16. Abbara A, Brooks T, Taylor GP, et al. Lessons for control of heroinassociated anthrax in Europe from 2009-2010 Outbreak Case Studies, London, UK. Emerg Infect Dis 2014;20:1115-22

17. Brachman PS. Inhalation anthrax. Ann N Y Acad Sci 1980;353:83-93

18. Ketai L, Alrahji AA, Hart B, et al. Radiologic manifestations of potential bioterrorist agents of infection. AJR Am J Roentgenol 2003;180:565-75

19. National Services Scotland on behalf of the National Anthrax Outbreak Control Team. An outbreak of anthrax among drug users in Scotland, December 2009 to December 2010. December 2011. http://www.documents.hps.scot.nhs.uk/giz/anthrax-outbreak/ anthrax-outbreak-report-2011-12.pdf. Accessed April 2, 2014
20. Tahernia AC, Hashemi G. Survival in anthrax meningitis. Pediatrics 1972;50:329-33

21. Kim HJ, Jun WB, Lee $\mathrm{SH}$, et al. CT and MR findings of anthrax meningoencephalitis: report of two cases and review of the literature. AJNR Am J Neuroradiol 2001;22:1303-05

22. Yildirim H, Kabakus N, Koc M, et al. Meningoencephalitis due to anthrax: CT and MR findings. Pediatr Radiol 2006;36:1190-93

23. Booth MG, Hood J, Brooks TJ, et al. Anthrax infection in drug users. Lancet 2010;375:1345-46

24. Hendricks KA, Wright ME, Shadomy SV, et al. Centers for Disease Control and Prevention expert panel meetings on prevention and treatment of anthrax in adults. Emerg Infect Dis 2014;20 doi: 10.3201/eid2002.130687

25. Tucker JB. Scourge: The Once and Future Threat of Smallpox. New York: Atlantic Monthly Press; 2001

26. Inglesby TV, Dennis DT, Henderson DA, et al. Plague as a biological weapon: medical and public health management-Working Group on Civilian Biodefense. JAMA 2000;283:2281-90

27. Bray RS. Armies of Pestilence: The Impact of Disease on History. Cambridege: James Clarke and Co; 2004

28. Becker TM, Poland JD, Quan TJ, et al. Plague meningitis: a retrospective analysis of cases reported in the United States, 1970-1979. West J Med 1987;147:554-57

29. Martin AR, Hurtado FP, Plessala RA, et al. Plague meningitis: a report of three cases in children and review of the problem. Pediatrics 1967;40:610-16

30. Jawetz E, Meyer KF. The behaviour of virulent and avirulent P. pestis in normal and immune experimental animals. $J$ Infect Dis 1944;74:1-13

31. Hofinger DM, Cardona L, Mertz GJ, et al. Tularemic meningitis in the United States. Arch Neurol 2009;66:523-27

32. Lovell VM, Cho CT, Lindsey NJ, et al. Francisella tularensis meningitis: a rare clinical entity. J Infect Dis 1986;154:916-18

33. van de Beek D, Steckelberg JM, Marshall WF, et al. Tularemia with brain abscesses. Neurology 2007;68:531-31

34. Anderson A, Bijlmer H, Fournier PE, et al. Diagnosis and management of $Q$ fever-United States, 2013: recommendations from CDC and the $\mathbf{Q}$ Fever Working Group. MMWR Recomm Rep 2013;62(RR-03):1-30

35. Schattner A, Kushnir M, Zhornicky T, et al. Lymphocytic meningitis as the sole manifestation of Q fever. Postgrad Med J 1993;69:636-37

36. Kofteridis DP, Mazokopakis EE, Tselentis Y, et al. Neurological complications of acute $\mathbf{Q}$ fever infection. Eur $J$ Epidemiol 2004;19:1051-54

37. Bernit E, Pouget J, Janbon F, et al. Neurological involvement in acute $Q$ fever: a report of 29 cases and review of the literature. Arch Intern Med 2002;162:693-700

38. Pappas G, Akritidis N, Bosilkovski M, et al. Brucellosis. N Engl J Med 2005;352:2325-36

39. Purcell BK, Hoover DL, Friedlander AM. Brucellosis. In: Dembek ZF, ed. Medical Aspects of Biological Warfare. Washington, DC: Borden Institute; 2007:185-98

40. Bilen Ş, Güneş HN, Saka M, et al. Four different clinical manifestations of neurobrucellosis (case reports). Eur J Intern Med 2008;19:e75-e77

41. Al-Sous MW, Bohlega S, Al-Kawi MZ, et al. Neurobrucellosis: clinical and neuroimaging correlation. AJNR Am J Neuroradiol 2004;25:395-401

42. Bossi P, Tegnell A, Baka A, et al. BICHAT guidelines for the clinical management of viral encephalitis and bioterrorism-related viral encephalitis. Euro Surveill 2004;9:E21-22

43. Misra UK, Kalita J. Overview: Japanese encephalitis. Prog Neurobiol 2010;91:108-20

44. Kalita J, Misra UK, Pandey S, et al. A comparison of clinical and radiological findings in adults and children with Japanese encephalitis. Arch Neurol 2003;60:1760-64

45. Kalita J, Misra UK. Comparison of CT scan and MRI findings in the diagnosis of Japanese encephalitis. J Neurol Sci 2000;174:3-8 
46. Ali M, Safriel Y, Sohi J, et al. West Nile virus infection: MR imaging findings in the nervous system. AJNR Am J Neuroradiol 2005;26: 289-97

47. Leis AA, Stokic DS, Polk JL, et al. A poliomyelitis-like syndrome from West Nile virus infection. N Engl J Med 2002;347:1279-80

48. Sejvar JJ, Leis AA, Stokic DS, et al. Acute flaccid paralysis and West Nile virus infection. Emerg Infect Dis 2003;9:788-93

49. Steele KE, Reed DS, Glass PJ, et al. Alphavirus encephalitides. In: Dembek ZF, ed. Medical Aspects of Biological Warfare. Washington, DC: Borden Institute; 2007:241-70

50. Deresiewicz RL, Thaler SJ, Hsu L, et al. Clinical and neuroradiographic manifestations of eastern equine encephalitis. N Engl J Med 1997;336:1867-74

51. Lury K, Castillo M. Eastern equine encephalitis: CT and MRI findings in one case. Emerg Radiol 2004;11:46-48

52. Silverman MA, Misasi J, Smole S, et al. Eastern equine encephalitis in children, Massachusetts and New Hampshire USA, 1970-2010. Emerg Infect Dis 2013;19:194-201

53. Alrajhi AA, Al-Semari A, Al-Watban J. Rift Valley fever encephalitis. Emerg Infect Dis 2004;10:554-55

54. Carod-Artal FJ, Wichmann O, Farrar J, et al. Neurological complications of dengue virus infection. Lancet Neurol 2013;12:906-19

55. Bhoi SK, Naik S, Kumar $S$, et al. Cranial imaging findings in dengue virus infection. J Neurol Sci 2014;342:36-41

56. Cam BV, Fonsmark L, Hue NB, et al. Prospective case-control study of encephalopathy in children with dengue hemorrhagic fever. $\mathrm{Am} \mathrm{J}$ Trop Med Hyg 2001;65:848-51

57. Chua KB. Nipah virus: a recently emergent deadly paramyxovirus. Science 2000;288:1432-35

58. Luby SP, Gurley ES, Hossain MJ. Transmission of human infection with Nipah virus. Clin Infect Dis 2009;49:1743-48

59. Lim CCT, Lee WL, Leo YS, et al. Late clinical and magnetic resonance imaging follow up of Nipah virus infection. J Neurol Neurosurg Psychiatry 2003;74:131-33

60. Sarji SA, Abdullah BJ, Goh KJ, et al. MR imaging features of Nipah encephalitis. AJR Am J Roentgenol 2000;175:437-42

61. Morens DM, Fauci AS. Chikungunya at the door: déjà vu all over again? N Engl J Med 2014;371:885-87

62. Burt FJ, Rolph MS, Rulli NE, et al. Chikungunya: a re-emerging virus. Lancet 2012;379:662-71

63. Economopoulou A, Dominguez M, Helynck B, et al. Atypical chikungunya virus infections: clinical manifestations, mortality and risk factors for severe disease during the 2005-2006 outbreak on Réunion. Epidemiol Infect 2009;137:534-41

64. Gérardin P, Barau G, Michault A, et al. Multidisciplinary prospective study of mother-to-child chikungunya virus infections on the island of La Reunion. PLoS Med 2008;5:e60

65. Whitehouse CA, Schmaljohn AL, Dembek ZF. Emerging infectious diseases and future threats. In: Dembek ZF, ed. Medical Aspects of Biological Warfare. Washington, DC: Borden Institute; 2007:579-607 